\title{
Desindividuação e emergência de normas sociais numa audiência: experiência de campo sobre o comportamento colectivo
}

\section{INTRODUÇÃO}

Dois artigos recentes (Stryker, 1977 e House, 1977) estabelecem uma distinção entre dois domínios diferentes em psicologia social: uma psicologia social psicológica e uma psicologia social sociológica. O campo da psicologia social psicológica é definido pela crescente focalização nos processos psicológicos dos indivíduos ao reagirem a estímulos sociais. $O$ método de investigação preferido é a experiência de laboratório onde as pessoas são expostas a situações sociais, (House, 1977: 163; Rabbie, Visser e van Oostrum, 1978). Segundo House (1977:

* J. M. R. é Psicólogo Social, Instituto de Psisologia Social. Universidade de Utrecht, Holanda. versão revista dum artigo apresentado no Enconto Geral da Associação Europeia de Psicologia Social Experimental em 1978, em Weimer, RDA. Este artigo baseia-se em material recolhido por Augustinus, van der Kruyssen \& Zoete (1972). O zutor agradece a esses autores pelo empenhamento 3 talento manifestados na elaboração, aplicação e ınálise da investigação, $O$ autor também manifesta > seu reconhecimento às autoridades militares que zutorizaram o recrutamento de sujeitos militares, ıssim como à NOS e outras Associações de Radiodijusão da Holanda que the forneceram os jornais televisivos utilizados neste estudo e à Fundação «Film sn Wetenschar» que deu a assistência técnica. $\mathrm{O}$ autor sstá profundamente reconhecido ao Prof. Norman Berkowitz e Prof. Philip Zimbardo pelas críticas consrutivas que fizeram a uma primeira versão deste irtigo. Este estudo foi financiado pela «Netherlands Jrganization for the Advancement of Pure Research» ZWO) com a bolsa n. ${ }^{\circ} 57,7$.
161-162), a psicologia social sociológica engloba duas variantes: «... o interaccionismo simbólico ... que se caracteriza pelo estudo da interacção social face-a-face através da observação natural ...» e «... a sociologia psicológica ... que relaciona fenómenos macrosociais ... com os atributos e o comportamento psicológico do indivíduo, utilizando, normalmente, métodos não-experimentais (sobretudo o inquérito)». Stryker e House lamentam estas fissuras actuais na psicologia social contemporânea e defendem um maior intercâmbio entre estas diferentes orientações. Este artigo representa um esforço preliminar nesse sentido, ao estudar o comportamento colectivo a partir de teorias e métodos desenvolvidos pelas diferentes tendências.

O estudo do comportamento colectivo é um exemplo evidente da crescente bifurcação em psicologia social. Os primeiros autores franceses e italianos (p. ex. Le Bon, 1887; Tarde, 1903; Sighele, 1895) explicaram o comportamento em multidão fundamentalmente em termos dos processos intra-individuais e inter-pessoais. Apreensivos com a agitação crescente decorrente dos alvores da «sociedade de massas» (Biddis, 1977), estes autores estavam mais impressionados com os aspectos emocionais, irracionais, e muitas vezes violentos; do comportamento das multidóes, do que em ver neles uma resposta racional dos «párias» a uma situa- 
ção insuportável. Nesse tempo, os psicólogos e os sociólogos de língua inglesa, como Ross (1908), McDougall (1920), Trotter (1916) e Martin (1920) tendiam a situar a essência do comportamento da multidão nas características dos participantes individuais nessa multidão, e nas interacções atípicas que ocorriam entre eles (Weller e Quarantelli, 1973). Até nas obras de sociólogos mođernos e influentes como Blumer (1946) e Park (1972), podem encontrar-se muitas passagens em que o indivíduo é usado como único ponto de referência para o comportamento em multidão (Aveni, 1977, pp. 96-97). A teoria da desindividuação é a moderna versão desta abordagem individualista do comportamento colectivo.

A teoria foi desenvolvida por «psicólogos sociais psicológicos» como Festinger, Pepitone e Newcomb (1952), Singer, Brush e Lublin (1965) e Zimbardo (1970). Ê notável que nenhum destes autores se refira ao trabalho redigido por sociólogos neste domínio. Por outro lado, os psicólogos sociais sociológicos que investigam os comportamentos colectivos parecem bastante desatentos aos desenvolvimentos da teoria da desindividuação. Numa revisão da teoria e da pesquisa no domínio dos comportamentos colectivos desenvolvidas nos últimos quinze anos, publicada na Annual Review of Sociology (Marx e Wood, 1975), não existem referências directas à teoria da desindividuação, num total de perto de 390 referências! Isto é surpreendente, já que a teoria da desindividuação e as abordagens com ela aparentadas deram origem a uma considerável quantidade de investigações, cuja revisão foi recentemente feita em revistas de psicologia (Dipboye, 1977; Diener, 1977).

Por volta do início da década de 60 , os sociólogos começaram a criticar a abordagem individualista dominante neste campo, e tentaram analisar os comportamentos colectivos em termos mais sociais (Turner e Killian, 1957, 1972; Smelser, 1964; Lang e Lang, 1961). Por exemplo, Turner (1964) e Turner e Killian (1972) propuseram uma «teoria da norma emer- gente» que sugere que o comportamento colectivo é governado por novas normas emergentes, que surgem em situações especiais. Mais recentemente verificaram-se, segundo Marx e Wood (1975), várias tentativas dos sociólogos no sentido de analisarem os comportamentos colectivos e convencionais no âmbito do mesmo quadro conceptual (Couch, 1968, 1970; Weller e Quarantelli, 1973; Berk, 1974). Weller e Quarantelli (1973), por exemplo, sugerem que os comportamentos institucionais e colectivos podem ser descritos através de duas dimensões socio-organizacionais: normas emergentes ou duradouras, e relações sociais emergentes ou duradouras. Na sua perspectiva, o comportamento colectivo está sempre associado a novas normas emergentes, a novas relações sociais emergentes, ou a ambas. Por exemplo, o comportamento em multidão entre amigos ou conhecidos pode implicar normas emergentes entre pessoas com relações sociais duradouras; ao passo que as multidões compostas por desconhecidos se caracterizam pela emergência de novas relações sociais $e$ de novas normas. Esta distinção entre multidões compostas por desconhecidos ou por conhecidos parece importante, à luz das investigações recentes que demonstram que, de facto, as multidões são compostas, quer por indivíduos isolados, quer por pessoas em grupo (Aveni, 1977). Por muito interessante que esta taxonomia de Weller e Quarantelli possa ser, não se relaciona claramente com qualquer teoria explicativa em que se possam basear as posições. Gostaríamos de explorar este problema neste artigo, e apurar se a teoria da desindividuação ou a teoria das normas emergentes podem proporcionar uma base para o estabelecimento dessas previsões.

\section{A teoria da desindividuação}

Desde o estudo clássico de Le Bon, La Psychologie des Foules (1895), os cientistas sociais ficaram fascinados pelo problema de saber em que condições as pessoas em multidão desen. volvem comportamentos impulsivos que usualmente reprimem. Em resposta a esta questão, 
Festinger et al. (1952, p. 389) sugeriram que as limitações internas à expressão de comportamentos usualmente inibidos são ultrapassadas num estado de «desindividuação». A desindividuação ocorre, afirmaram, num grupo em que os membros não são vistos ou em que não se dá atenção ao comportamento dos indivíduos e, consequentemente, os membros do grupo «sentem que não são individualizados pelos outros membros do mesmo grupo». Os grupos que proporcionam condições para a desindividuação e para a «redução das limitações internas são mais atractivos para os seus membros do que as situaçôes em que isso não acontece. Um artigo influente de Zimbardo (1970) representa um desenvolvimento ulterior desta teoria. Segundo este autor, as pessoas deparam com uma escolha fundamental entre a individuação, a razão e a ordem, e a desindividuação, o impulso e o caos. Fenómenos tais como a autodestruição e a destruição dos outros, o vandalismo, desordens sociais e violência colectiva, são exemplos de comportamentos de desindividuação - mas também o carnaval, os «grupos de encontro» e as orgias sexuais pertencem, na sua opinião, a esta categoria.

Zimbardo (1970) ampliou a teoria de Festinger et al. (1952), especificou algumas condições antecedentes ou «variáveis de input» incluindo a activação emocional, o anonimato e a presença grupal, etc., e algumas «variáveis de output» tais como os comportamentos emocionais e impulsivos, a hiper-reactividade ao comportamento de outros, quando próximos e activos, possíveis bloqueios mnésicos e distorções perceptivas, e «uma maior preferência por grupos ou situações associadas com o comportamento manifesto» (p. 253). Estas variáveis de input $\mathrm{e}$ de output são mediadas por um estado interno designado «desindividuação» caracterizado pela minimização da auto-avaliação, uma menor preocupação com os juízos dos outros, um enfraquecimento dos mecanismos de controlo baseados nos sentimentos de culpa, vergonha $\mathrm{e}$ medo, e uma diminuição do limiar de expressão de comportamentos inibidos (Zimbardo, 1970, p. 253) ${ }^{1}$. Ainda que Zimbardo não o afirme explicitamente, poderia argumentar-se que, se a expressão dos sentimentos impulsivos é gratificante em si mesma e por si mesma, é provável que as pessoas se sintam mais aliviadas, satisfeitas e relaxadas após a manifestação desses comportamentos impulsivos do que antes. De acordo com a teoria de Zimbardo, todas as condições que garantem o anonimato induzem um mais elevado grau de desindividuação, e conduzem, consequentemente, a um comportamento mais impulsivo, a bloqueios mnésicos, a atracção pelo grupo, etc. Por definição, os desconhecidos são mais anónimos do que os conhecidos. Portanto, uma implicação possível da teoria da desindividuação seria a de que as multidões compostas por desconhecidos denotariam mais comportamentos impulsivos etc., do que as compostas por grupos de conhecidos. Zimbardo rejeita explicitamente a ideia de que o comportamento desindividualizado possa ser compreendido como um aspecto do «simples comportamento conformista em resposta a uma nova norma que é aceitável» (Zimbardo, 1970, p. 262).

\section{A teoria da norma emergente}

Esta teoria de Turner (1964) e de Turner e Killian (1972) representa o ponto de vista oposto. Segundo a teoria, os membros das multidões estão primordialmente motivados para atingir uma norma comum, uma compreensão partilhada do tipo de comportamento que deles se espera. «A partilha dessa compreensão encoraja o comportamento consistente com a norma, inibe o comportamento que lhe seja contrário, e justifica a acção contra os indivíduos que dela dissidem. Na medida em que a norma é de algum modo específica à situação, e é diferente em grau ou em qualidade das normas que governam as situações diversas da situação de multidão, trata-se de uma norma emergente.) (Turner e Killian, 1972, p. 22). Estes

\footnotetext{
1 Se bem que Zimbardo não se refira à obra de Blumer (1946) é patente que usa alguns termos semelhantes aos utilizados por Blumer $(1946$, p. 118) para descrever os participantes individuais na multidão.
} 
autores criticam as teorias que realçam os efeitos desencadeadores do anonimato: «Se o comportamento em multidão resulta da ausência de controlo social ou da libertação das ten dências reprimidas, então o anonimato seria efectivamente de primordial importância para a eliminação dos mecanismos de controlo que habitualmente sustêm os impulsos. Se, todavia, o comportamento em multidão está sujeito ao controlo social por efeito de uma norma emergente, é importante que o indivíduo na multidão tenha uma identidade, de forma a que o controlo da multidão seja efectivo. Devemos, assim, procurar factos que testem a hipótese de que o controlo da multidão é maior com pessoas que se conhecem uma às outras do que entre pessoas anónimas» (Turner e Killian, 1972, p. 24).

\subsection{A Familiaridade}

Se bem que o controlo da multidão possa ser maior entre conhecidos do que entre desconhecidos anónimos, o facto de os conhecidos denotarem mais ou menos comportamentos impulsivos do que os desconhecidos dependerá do tipo de normas emergentes. Segundo Berk (1974, p. 370), o ênfase teórico na perspectiva das normas emergentes está no papel das normas em moldar o comportamento em multidão, e não na razão porque uma dada norma ou conjunto de normas despontam em situações de multidão. Para se fazerem previsões a partir desta teoria, são necessárias hipóteses complementares. É possível que as normas emergentes entre conhecidos favoreçam mais a expressão do comportamento impulsivo do que as normas que se desenvolvem entre grupos de desconhecidos. As normas formam-se quando as pessoas, numa situação ambígua, se comparam entre si de modo a saber qual é a «definição da situação» e que tipo de comportamento se espera delas (Festinger, 1954; Gerard e Rabbie, 1961). Estes processos de comparação «informativos» e «normativos» (Deutsch e Gerard, 1955) são facilitados quandos as pessoas são bem conhecidas umas das outras. Sugeriu-se que os ami- gos tendem a ser mais aceitantes e apoiantes uns dos outros do que os desconhecidos (Zabrac e Miller, 1972). Portanto, é possível que os conhecidos demonstrem uma mais vasta gama de comportamentos que podem ser usados como base para a comparação social do que os desconhecidos. Sentem-se mais à vontade uns com os outros, e sentirão que é mais fácil interagir e comparar-se entre si do que com desconhecidos. Além disso, os conhecidos ou os membros de grupos duradouros desenvolveram um quadro de referência comum que os ajuda a interpretar e a prever as reacções dos co-agentes para consigo próprios, e para com a situação (Berk, 1974, p. 367). Aos desconhecidos falta esse quadro de referência comum, e acharão mais difícil prever, por exemplo, quando é que os outros desconhecidos aprovam ou desaprovam os seus comportamentos. Assim, é mais provável que adoptem uma atitude de expectativa e sentir-se-ão mais constrangidos e inibidos do que os conhecidos, que tendem a ser aceitantes e apoiantes uns dos outros. Há um certo número de factos que corroboram esta hipótese. Num estudo pioneiro sobre as reacções de grupos, organizados e não organizados, ao medo e à frustração, verificou-se que os membros (conhecidos) dos grupos organizados eram muito livres e desinibidos entre si, ao passo que os grupos não-organizados compostos por desconhecidos eram controlados, envergonhados, sem à vontade social, especialmente no início das experiências (French, 1944). Num outro estudo, planeado para testar os efeitos dos laços de amizade e do anonimato (Zabrac e Miller, 1972), foram verificados mais comportamentos agressivos entre grupos de amigos do que entre desconhecidos, especialmente quando se podiam ver e comparar entre si.

Turner não se refere a outros efeitos do anonimato ou da identificabilidade sobre variáveis tais como a atracção pelo grupo, a aceitação de si próprio, o bloqueio mnésico, etc. Todavia não parece despropositado supor que a atraç̧ão pelo grupo e a aceitação e satisfação consigo próprio aumentem à medida que as pessoas se conformam mais com as normas 
(emergentes). A investigação demonstrou que quanto maior é a coesão grupal, maiores são as pressões para a uniformidade (Cartwright e Zander, 1968). Quando os membros são recompensados pelo seu conformismo pelas reacções de aprovação e pela aceitação social, é plausível que, por seu turno, se sintam mais atraídos pelo seu grupo, e se sintam mais aceitantes e satisfeitos consigo mesmos (Aronson, 1970; Lott e Lott, 1965). Deste modo, esta versão alargada da teoria das normas emergentes permitiria prever menor inibição, mais comportamentos impulsivos, maior atracção pelo grupo e contentamento consigo mesmo, em grupos de conhecidos do que entre grupos de desconhecidos.

\subsection{Escuridão e luz}

É central no argumento de Zimbardo que, à medida que o anonimato aumenta, as pessoas não podem ser identificadas como indivíduos responsáveis, e que portanto não esperam que sejam aplicadas sanções negativas aos seus comportamentos impulsivos. Quando as pessoas são colocadas numa sala obscurecida, é mais difícil identificá-las como indivíduos responsáveis, do que numa sala iluminada, quando são claramente visíveis uns para os outros. Portanto, sob a protecção da escuridão, as pessoas sentem-se mais desindividualizadas e consequentemente demonstrarão mais comportamentos impulsivos, bloqueios mnésicos $\mathrm{e}$ atracção pelo grupo do que numa sala iluminada.

De acordo com a nossa versão da teoria das normas emergentes, dependerá do tipo de normas que emergirem, o facto de a maior identificabilidade na sala iluminada dar azo a mais ou menos comportamentos impulsivos. Foi anteriormente argumentado que, entre os conhecidos, as normas emergentes serão mais tolerantes ou permissivas em relação à expressão dos comportamentos impulsivos do que as que se desenvolvem em grupos de desconhecidos. Por exemplo, é plausível que inicialmente os conhecidos se sintam mais livres para gritar e barafustar quando assistem a um filme activante do que os desconhecidos, que se sentirão mais inseguros, duvidando se esse tipo de comportar mento impulsivo será ou não adequado. Terão mais dificuldade em interpretar as reacções dos outros desconhecidos: não sabem se eles aprovam ou desaprovam essas formas de comportamento impulsivo. Deste modo, sentir-se-ão mais inibidos para gritar e barafustar do que os conhecidos. Se este argumento for correcto, a teoria das normas emergentes permitiria prever que a maior identificabilidade entre conhecidos na sala iluminada conduziria a comportamentos mais impulsivos e menos inibidos, maior atracção pelo grupo e maior satisfação consigo próprio, do que na sala obscurecida. Em relação aos desconhecidos, verificar-se-ia o contrário. Além disso, já que as pessoas têm mais dificuldade em se identificarem umas às outras no escuro do que numa sala iluminada, a diferença entre conhecidos e desconhecidos será mais pronunciada, quando a sala está iluminada, do que no escuro.

\subsection{Proximidade física}

Tanto a teoria das normas emergentes como a teoria da desindividuação sublinham a importância dos factores ecológicos. Segundo Turner e Killian (1972, p. 62) «qualquer disposição especial das pessoas que aumente as oportunidades para a comunicação espontânea e nã̃ocrítica, aumenta a propensão para o comportamento colectivo». Presumivelmente, a estreita proximidade física propicía oportunidades para as «comunicações espontâneas e não-críticas» que facilita a emergência de uma norma temporária, encorajando o comportamento impulsivo, especialmente entre pessoas que se conhecem umas às outras.

Como vimos, Zimbardo (1970) rejeita o ponto de vista de que o comportamento desindividualizado pode ser entendido como um exemplo do mero comportamento conformista em resposta à percepção de uma nova norma que é aceitável. Segundo este autor, a proximidade física «estimula o contágio comporta- 
mental, que não é mediado pela tomada de consciência cognitiva das pressões em ordem à uniformidade grupal, mas por uma consciencialização sensorial do comportamento de outros que se situam dentro dos limites do espaço pessoal do sujeito ...» (Zimbardo, 1970, p. 262).

Apesar destes pontos de vista opostos, ambas as teorias poderiam prever que a estreita pro. ximidade entre os membros de uma multidão conduziria a comportamentos mais impulsivos do que quando estão fisicamente afastados uns dos outros. Todavia, os desconhecidos poderiam reagir de forma bastante diferente dos conhecidos, em relação às variações da distância física. Se bem que a proximidade física possa proporcionar mais oportunidades para a «comunicação espontânea e não-crítica» (Turner) e para o «contágio comportamental». (Zimbardo) do que a separação física, os desconhecidos podem sentir-se menos à vontade na interacção uns com os outros do que os conhecidos (Argyle, 1969; Sommer, 1969). Mesmo quando se verifica uma maior interacção social entre desconhecidos quando estão sentados uns perto dos outros do que quando estão sentados afastados uns dos outros, a nossa versão da teoria das normas emergentes seria aplicável, ou seja: desenvolver-se-iam normas que exerceriam uma infuência inibidora da expressão do comportamento impulsivo entre estranhos, mas que encorajariam este tipo de comportamento entre conhecidos. Neste caso, seria de prever mais comportamentos impulsivos entre conhecidos na situação de proximidade do que na situação de afastamento. Para os desconhecidos, verificar-se-ia o oposto. Dado que a teoria da desindividuação rejeita a ideia de que a expressão do comportamento impulsivo seja regida por novas normas acerca do que é aceitável, não são de esperar efeitos de interacção entre diferentes graus de proximidade física e de conhecimento pessoal.

Um dos principais problemas do estudo dos comportamentos colectivos é o desenvolvimento de uma metodologia adequada. Um inquérito junto de sociólogos que trabalham na área do comportamento colectivo, revelou que a maioria dos inquiridos atribuiu os sérios fracassos nesta especialidade ao tipo de teorias, métodos e dados obtidos neste domínio (Quarantelli e Weller, 1974, p. 64). Especialmente a fragilidade metodológica, é um problema grave. Marx e Wood $(1975$, p. 373$)$ colocam muito bem a questão: «A imprevisibilidade do comportamento colectivo $\mathrm{e}$ as dificuldades práticas $\mathrm{e}$ éticas para o investigar ao vivo, sugerem a necessidade de uma abordagem experimental em que o investigador estipula condições e manipula as variáveis que considera importantes ... Há limitações, no entanto, para esta abordagem experimental, incluindo a artificialidade das experiências; a incapacidade para recrear as condições genuinas da espontaneidade, da indignação ou do medo que estão tantas vezes envolviđas no comportamento colectivo a sério....). Outros investigadores criticaram as deficiências das experiências laboratoriais nesta área (Milgram e Toch, 1969; Zimbardo, 1970; Diener, 1977). Se as experiências laboratoriais bem controladas não podem ser realizadas, então teremos que ficar pelo exame de alguns aspectos do comportamento colectivo, nas condições menos rigorosas da experimentação de campo. Segundo Berk (1974, p. 368): «... há a convicção geral de que o comportamento colectivo implica comportamentos relativamente espontâneos e transitórios das pessoas em estreita proximidade umas com as outras». Pareceu-nos que este tipo de comportamento poderia ser elicitado numa situação em que uma audiência assistisse a um filme emocionalmente excitante, numa sala relativamente pequena. Um estudo piloto confirmou essa esperança. Nessas «multidões inactivas» (Evans, 1969, p. 7) as pessoas ficavam indignadas com a maneira como os civis eram tratados pela polícia, nos filmes de noticiário apresentados. Faziam comentários obscenos em relação à polícia, e desataram à gargalhada quando um polícia perdeu a sua matraca, etc., etc. Em suma: pereceu-nos análogo a alguns comportamentos que são observáveis nas multidões activas. 


\section{MÉTODO}

\subsection{Sujeitos}

Participaram na experiência, realizada numa base do exército holandês, 638 sujeitos do sexo masculino (doravante designados por Ss), todos militares, soldados e cabos, no primeiro ano de serviço e com cerca de 20 anos de idade. Cerca de duas semanas antes da experiência, os $S$ s eram solicitados a oferecer-se como voluntários. $O$ experimentador $(E)$ disse-lhes que estávamos interessados nas reacções das pessoas a um filme que seria projectado em condições diversificadas: por exemplo, quando a sala estava iluminada ou às escuras, com $e$ sem som, etc. Este pedido não lhes pareceu insólito, já que frequentemente lhes era pedida a reacção a filmes de instrução militar que viam regular. mente.

\subsection{Plano e procedimento}

Trinta grupos de $20 \mathrm{Ss}$ e dois grupos de 19 Ss foram aleatoriamente constituídos e distribuidos pelas oito condiçôes experimentais. Em metade desses 32 grupos, os $S_{s}$ conheciam-se bastante bem, já que pertenciam ao mesmo pelotão. Na restante metade dos grupos os $\mathrm{Ss}$ conheciam-se menos bem, já que nos esforçámos por constituir grupos de Ss pertencentes a pelotões diferentes. Aconteceu ocasionalmente, porém, que não havia pelotões disponiveis em numero suficiente, o que fez com que, por vezes, 4 a 6 dos vinte homens pertences sem ao mesmo pelotão. Contudo, duma maneira geral, o grau de familiaridade ou conhecimento inter-pessoal era muito mais elevado nos grupos que se conheciam bem do que nos que se conheciam mal.

Em cada uma destas condições experimentais, o material estímulo era apresentado numa sala às escuras (escuridão) de modo que os Ss não conseguiam praticamente ver-se uns aos outros, ou numa sala iluminada (luz) com luz suficiente para que as pessoas se identificassem facilmente umas às outras, sem chegar a prejudicar a visão do filme. Os Ss estavam sentados em quatro filas de cinco lugares. $\mathrm{Na}$ condição de proximidade, próximo, as cadeiras estavam separadas por uma distância de cerca de $15 \mathrm{~cm}$, ou de cerca de 6 polegadas, numa mesma fila. Na condição afastado a distância entre as cadeiras era cerca de 1 metro (ou cerca de 3 pés). Recomendava-se muito aos sujeitos que não deslocassem as cadeiras durante a ses- são. As cadeiras estavam numeradas de modo a serem identificadas.

$O_{S} S s$ foram informados em todas as condições experimentais de que havia dois microfones pendurados no teto. Explicou-se-lhes que esses microfones se destinavam a gravar numa sala contígua o volume de ruído que eles faziam. Todos foram informados, uma vez que os sujeitos na condição luz se apercebiam mais facilmente dos microfones do que os sujeitos na condição escuridão. Esperávamos utilizar o volume de som como um indicador do comportamento impulsivo. Infelizmente, estes dados não puderam ser analizados devido a um mau contacto no equipamento de gravação.

\subsection{Material estímulo}

Após uma breve apresentação do objectivo da experiência mostravam-se dois filmes video num monitor video $59^{\circ}$. $O$ monitor video estava colocado num estrado a cerca de dois metros e meio (2,5 jardas) da primeira fila de modo que cada sujeito visse claramente o écran. $O$ técnico responsável do gravador video estava sentado no fundo da sala.

O material estímulo compunha-se de três partes:

A) Em primeiro lugar, para familiarizar os Ss com a situação experimental, passava-se um filme neutro, em que um artista apresentava uma nova técnica de modelagem dos plásticos que usava na sua escultura. Era um filme sonoro com uma duração de cerca de 5 minutos e trinta segundos.

B) $O$ material estímulo crítico consistia em dois fragmentos de filmes de distúrbios em Amsterdão que já tinham sido passados na televisão holandesa. $O$ primeiro fragmento, intitulado "polícia municipal», mostrava uma cena bastante calma em que a polícia procurava calmamente conter as multidões exaltadas. No segundo fragmento, chamado «unidades móveis», mostravam-se graves confrontos entre a polícia e os manifestantes e algumas cenas mostravam a polícia a agredir severamente os manifestantes (cena agressiva).

Ambos os filmes tinham uma duração de cerca de 5 minutos e 45 segundos.

C) Como todos os sujeitos esperavam ver um filme completo fizémos apresentaçồs de três filmes. Pediase aos sujeitos que seleccionassem o que pretendiam ver integralmente. Cada apresentação durava cerca de 1 minuto. $O$ primeiro fragmento intitulado «World of Stone» repre- 
sentava um plano duma montanha escarpada com rochas a caír. $O$ segundo, «Seven Pistols for McGregor» apresentava cenas agressivas extraídas dum western. Na terceira apresentação, «Dream Girls», aparecia uma cena erótica em que uma mulher atraente em roupão olhava para um jovem impaciente. $O$ material estímulo era apresentado sem som a fim de gravar o volume de ruído na sala. Esperava-se uma maior preferência pelo material impulsivo - erótico ou agressivo - nas condições facilitadoras da emergência de comportamento impulsivo. A preferência pelo filme principal era expressa pondo o braço no ar. Estas preferências foram registadas através da anotação do número da cadeira ocupada pela pessoa.

\subsection{Medidas}

Depois dos sujeitos terem manifestado as suas preferências pelo filme principal, levantando o braço, respondiam a um questionário post-experimental que continha escalas de sete pontos, tipo Likert. Este questionário incluia as seguintes medidas:

1) Avaliação do filme. Os sujeitos tinham que fazer estimativas da duração dos dois filmes informativos que tinham visto. Esperava-se que o filme agressivo mais atraente fosse sentido como mais curto do que a cena mais calma, menos atraente (Ornstein, 1969). Também lhes pedimos que pusessem por escrito o filme principal que desejavam ver. Se houvesse mais preferências por um determinado filme com o levantar do braço do que por escrito, isto poderia ser um indicador do grau de contágio comportamental no grupo (Wheeler, 1969). Finalmente, tinham que caracterizar as acções da polícia, com base em certos adjectivos seleccionados.

2) Normas sobre comportamento impulsivo. Procurámos detectar estas normas através das seguintes perguntas: "Geralmente costumo fazer comentários em voz alta durante a exibição dum filme» $e$ "Duma maneira geral, quando assisto a um filme incomoda-me ouvir comentários em voz alta» $e$ «Neste preciso momento os comentúrios dos outros incomodam-mes.

3) $O$ grau de inibição era medido por dois itens. «Sinto-me à vontade (ou pouco à vontade) para fazer comentários em voz alta quando assisto a um filme» $e$ «Nesta situação sinto-me como uma cobaias.

4) Comportamento impulsivo. Procurámos medir este comportamento através de pergun- tas relativas ao «estado de espírito» do grupo $e$ às reacções do grupo ao filme. $O$ estado de espírito do grupo foi medido por uma escala de diferencial semântico de sete pontos com os seguintes opostos especificos: entusiasmado, não entusiasmado, aborrecido-empenhado, apático-animado, e uma pergunta sobre como as pessoas tinham sido sensiveis ao comentários dos outros, ouvidos na sala, e aos seus próprios comentários.

5) $A$ atracção pelo grupo foi medida através de perguntas do tipo «Sinto-me só ou inserido no grupo» $e$ «Sinto me satisfeito por estar neste grupo».

6) $A$ satisfação consigo próprio era apreciada por perguntas do tipo «Enquanto assisto ao filme sinto-me livre», "satisfeito», «descontraído», «empenhado» $e$ «à vontade».

7) Controlos das condições experimentais. Pedia-se aos Ss que indicassem se "gostavam ou não de estar com pessoas conhecidas» $e$ se "gostavam de estar mais perto ou mais longe uns dos outros».

8) Testes de memória. Depois de terem preenchido o questionário post-experimental mostravam aos sujeitos catorze fotografias, metade das quais representavam cenas «calmas» ou «agressivas». Seis delas (três cenas calmas e três agressivas) já tinham sido apresentadas (verdadeiras) sendo as outras oito de filmes que os Ss não tinham visto (falsas). Perguntava-se aos $S_{s}$ se tinham ou não visto estas cenas $e$ em que medida tinham a certeza de as reconhecer. Estes testes de memória destinavam-se a obter medidas do funcionamento cognitivo dos sujeitos nas condições experimentais. Pretendiamos verificar, com estas medidas: a) se as cenas agressivas ou estimulantes seriam mais facilmente recordadas do que as cenas mais calmas; b) se os $S$ se lembravam melhor ou pior das cenas realmente apresentadas; c) se os $S_{s}$ que manifestam comportamento impulsivo são os que provavelmente, se «lembram» de cenas agressivas que, de facto, não tinham sido exibidas.

9) Formulário de recrutamento. Pedia-se aos sujeitos que respondessem num formulário, se seriam ou não voluntários para uma experiência semelhante, a fim de obter uma medida comportamental do seu interesse $e$ atracção pela experiência.

10) Controle interno-externo. Visto que haveria, certamente, diferenças de personalidade na maneira como os individuos se sentiam expos- 
tos a forças externas, aplicou-se uma versão holandesa da Escala de Locus de Controlo interno-externo (Rotter, 1966). Devido a limitações de espaço, os resultados deste questionário serão apresentados noutro lugar (Rabbie e Visser, 1978). Perante a natureza exploratória deste estudo, limitaremos a discussão dos resultados aos dados do questionário post-experimental e dos testes de memória que produziram resultados estatisticamente significativos.

\section{RESULTADOS}

3.1. O Quadro I apresenta os dados do questionário post-experimental. Tal como pensávamos, aqueles que se conhecem «preferem mais estar com pessoas suas conhecidas» do que os que não se conhecem (p .025). Os indivíduos da condição proximidade preferiam sentar-se um pouco mais distantes - não podiam sentar-se mais próximos do que já estavam enquanto que os da condição afastamento gostariam de se sentar um pouco mais próximos $(\mathrm{p}<.001)$.

\subsection{Familiaridade}

Se partirmos do princípio que os indivíduos que não se conhecem são mais anónimos do que os que se conhecem, a teoria da desindividuação prediria que os desconhecidos se sentiriam menos inibidos, e mostrariam mais comportamento impulsivo, atracção pelo grupo e satisfação consigo próprios do que os sujeitos que se conhecem. A nossa versão da teoria das normas emergentes faria a predicção contrária. Como se pode ver no Quadro I, há mais fundamento para a teoria das normas emergentes do que para a hipótese da desindividuação.

Os Ss recrutados num mesmo pelotão afirmaram com mais frequência «que costumavam fazem comentários em voz alta durante o filme» do que os indivíduos que pertenciam a pelotões diferentes $(\mathrm{p}<.005)$, e também «que se sentiam menos incomodados com os indivíduos que faziam esses comentários» do que os indivíduos que não se conheciam $(\mathrm{p}<.05)$. De acordo com as nossas expectativas estas descobertas sugerem que os indivíduos que não se conhecem se sentem mais confinados às normas que regulam a expressão deste tipo de comportamento impulsivo do que os que se conhecem, que podem já ter desenvolvido normas mais encorajadoras do que limitadoras dum tal comportamento.

Do mesmo modo, os que se conhecem bem apresentam mais comportamento impulsivo do que os que não se conhecem. Comparativamente com os que não se conhecem, os que se conhecem bem descrevem as reacções do grupo como sendo mais «entusiásticas» $(\mathrm{p}<.001)$, mais «animadas» $(\mathrm{p}<.001)$, menos «incomodativas» $(\mathrm{p}<.001)$ e mais «calorosas» $(\mathrm{p}<.001)$.

Os que se conhecem bem também se sentem mais atraídos pelo grupo: sentem-se mais «satisfeitos» $(\mathrm{p}<.005)$ e «inseridos» $(\mathrm{p}<.025)$ no grupo do que os que se conhecem mal.

Os que se conhecem bem também se sentem mais satisfeitos consigo próprios do que os que se conhecem mal. Sentem-se mais «satisfeitos» $(\mathrm{p}<.025)$ e «empenhados» $(\mathrm{p}<.05)$ ao assistir ao filme, do que os que se conhecem mal.

Houve apenas uma diferença significativa no funcionamento cognitivo dos que se conhecem bem e dos que se conhecem mal. Os indivíduos que se conheciam bem apresentavam um maior bloqueio mnésico do que os que se conheciam mal. Houve maior tendência entre os que se conheciam bem para «reconhecer» fotografias agressivas falsas $(M=28.38)$, do que entre os que se conheciam mal $(M=26.64 ; F=5.17$; $\mathrm{df}=1.24$ ). Esta descoberta reflete, talvez, um caso de projecção. Os indivíduos excitados tendem a distorcer a realidade no sentido do seu próprio comportamento impulsivo: «lembram-se» de cenas agressivas que de facto não foram exibidas.

\subsection{Escuridão e luz}

Segundo a teoria da desindividuação, as pessoas deveriam sentir-se mais anónimas, menos inibidas e apresentariam mais comportamento impulsivo, atracção pelo grupo e sentir-se-iam mais satisfeitas consigo próprias numa sala às escuras do que numa sala iluminada. 
A teoria das normas emergentes predizia que os conhecidos e os desconhecidos se comportariam de maneira diferente numa sala às escuras e numa sala iluminada, consoante o tipo de normas que tivesse emergido.

Os raros efeitos principais que se vêem na coluna 1 do Quadro I representam resultados contraditórios. Contrariamente à hipótese da desindividuação, parece que os indivíduos se comportam de forma menos impulsiva na condição escuridão do que na condição luz: na sala às escuras sentiam-se mais incomodados com «as reacções do grupo» $(\mathrm{p}<.025)$ e consideravam a atmosfera do grupo «mais fria» $(\mathrm{p}<.05)$ do que os sujeitos da condição luz. Também estavam ligeiramente mais «habituados a fazer comentários em voz alta» na condição luz do que na condição escuridão $(\mathrm{p}<.10)$. Em consonância com a hipótese da desindividuação, os sujeitos na condição escuridão manifestaram satisfação e contentamento com mais frequência: sentiam-se mais «à vontade» entre si durante a exibição do filme do que na sala iluminada $(\mathrm{p}<.025)$. Os sujeitos da condição Iuz $(\mathrm{M}=30.67)$ lembravam-se com mais facilidade das fotografias calmas-verdadeiras que tinham sido apresentadas do que os sujeitos na condição escuridão $(M=27.95 ; F=7.08 ; \mathrm{df}=1,24$; $\mathrm{p}<.025)$. Esta descoberta está de acordo com a hipótese da desindividuação. Porém, os sujejtos no escuro fizeram menos erros de identificação. «Reconheceram» menos vezes fotografias agressivas que não tinham sido de facto apresentadas $(M=26.60)$ do que os Ss na condição Iuz $(\mathrm{M}=28.36 ; \mathrm{F}=4.94$; df 1,$24 ; \mathrm{p}<.05)$. $\mathbf{E}$ possível que estas medidas detectem graus diferentes de bloqueio cognitivo.

As interacções significativas entre o grau de iluminação e o conhecimento na coluna 5 do Quadro I estão mais de acordo com a teoria das normas do que com a hipótese da desindividuação. A teoria das normas predizia que entre os que se conheciam bem iam emergir normas que encorajariam a expressão de comportamento impulsivo, enquanto que as normas emergentes entre os que se conheciam mal teriam uma influência mais restritiva. $\mathrm{Na}$ sala iluminada, o impacto diferencial destas normas seria maior na condição luz do que na condição escuridão. De acordo, em parte, com esta noção, os desconhecidos sentem-se mais inibidos: sentem-se mais «cobaias» na condição luz do que na condição escuridão. Para os que se conhecem bem há uma tendência no sentido contrário $(\mathrm{p}<.025)$. Certos itens utilizados para detectar o estado de espírito impulsivo do grupo apresentaram um padrão semelhante de resultados. Os que se conheciam bem descreveram as reacções do grupo como sendo mais «animadas $(\mathrm{p}<.05)$, «mais simpáticas» $(\mathrm{p}<.05) \mathrm{e}$ «mais calorosas» $(\mathrm{p}<.005)$ na condição luz do que na condição escuridão, enquanto para os desconhecidos estas diferenças entre as condições luz e escuridão não foram relevantes. Digamos, por outras palavras, que: duma maneira geral, os que se conheciam bem descreveram 0 estado de espírito do grupo nestes itens como sendo mais emocional e impulsivo do que os que se conheciam mal, sendo estas diferenças entre os que se conheciam mal mais acentuadas na condição luz do que na condição escuridão, tal tal como havíamos previsto.

As perguntas relativas à atracção pelo grupo: «satisfeito com o grupo» $(\mathrm{p}<.01)$ e «inserido no grupo» $(\mathrm{p}<.025)$ revelaram interacções semelhantes. Uma vez que a teoria da desindividuação só prediz efeitos principais e não efeitos de interacção, estas interacções poderiam ser interpretadas como um fundamento da teoria das normas emergentes.

\subsection{Proximidade física.}

Ambas as teorias prediziam menor inibição, maior impulsividade, atracção pelo grupo e satisfação pessoal na condição "próximo» do que na condição «afastado». Apesar destas predicções obtivemos muito poucos efeitos principais significativos (ver coluna 2 no Quadro I).

De facto, os sujeitos sentiam-se mais desinibidos na condição próximos do que na condição afastados: quanto mais próximos estavam «mais à vontade se sentiam para fazer comentá- 
rios em voz alta durante a exibição do filme» $(\mathrm{p}<.05)$.

A proximidade física produziu sobretudo efeitos de interacção, em especial com a variável familiaridade (ver coluna 4, Quadro I). Estas interacções parecem estar mais de acordo com a teoria das normas emergentes do que com a hipótese da desindividuação. Esperávamos que os desconhecidos, que agiam sob normas restritivas, se sentissem mais inibidos, mostrassem menos comportamento impulsivo, atracção pelo grupo e menos satisfação pessoal na condição próximos do que na condição afastados. A tendência deveria ser oposta para os sujeitos que se conheciam bem. De acordo com a hipótese das normas, os desconhecidos sentem-se de certo modo mais «cobaias» na condição próximos do que na condição afastados, enquanto que a tendência entre os que se conheciam bem era de sentido contrário $(\mathrm{p}<.025)$. $O$ estado de espírito do grupo foi descrito pelos que se conheciam bem como sendo mais emocional e impulsivo para os que se sentavam próximos do que para os que se sentavam mais afastados, enquanto que os desconhecidos reagiram com mais impulsividade na condição afastados do que na condição próximos. Obtivemos interaç̧ões significativas entre estas duas variáveis nos itens: o estado de espírito do grupo era «entusiasmado» $(\mathrm{p}<.025)$, «empenhado» $(\mathrm{p}<.005)$, «animado» $(\mathrm{p}<.001)$, «caloroso» $(\mathrm{p}<.025)$ e «agradável» $(\mathrm{p}<.01)$. Observamos interacções semelhantes em itens que mediam a atracção pelo grupo: «satisfeito por estar no grupo» $(\mathrm{p}<.001)$ e «inserido no grupo» $(\mathrm{p} ₹ .025)$. As questões relativas à satisfação consigo próprio apresentaram efeitos de interacção semelhantes nos itens «sinto-me satisfeito» $(\mathrm{p}<.005)$, «empenhado» $(\mathrm{p}<.005)$ e «descontraído» $(\mathrm{p}<.001)$ a assistir ao filme.

Os dados sobre reconhecimento apresentam um padrão semelhante de resultados. Os que se conhecem bem lembram-se melhor de cenas «calmas» e «agressivas», efectivamente exibidas, na condição próximos do que na condição afastados.
Entre os que se conheciam mal a tendência é oposta. Para os que se conheciam bem os principais valores de reconhecimento de fotografias calmas verdadeiras são de 31.5 e 28.3, para as condições próximos e afastados respectivamente. Para os que se conheciam mal, estes números são de 28.1 para a condição próximos e de 29.3 para a condição afastados $(F=4.69$; df. 1,$24 ; \mathrm{p}<.05$ ). Para os que se conheciam bem, os principais valores de reconhecimento das fotografias agressivas verdadeiras são de 38.5 na condição próximos e de 36.1 na condição afastados. No caso dos que se conheciam mal estes números são respectivamente de 73.3 e $37.9(\mathrm{~F}=4.48$; df.1,24; $\mathrm{p}<.05)$.

Estes resultados podem significar que, contrariamente à hipótese da desindividuação, quanto mais o material cognitivo mostrado anteriormente fôr acompanhado de envolvimento emocional e impulsividade, melhor os indivíduos o registam e processam.

Verificam-se duas interacções significativas entre as condições próximos/afastados e escuridão/luz (ver coluna 4 do Quadro I). Contrariamente à hipótese da desindividuação, os indivíduos numa sala iluminada sentem-se mais «à vontade» $(\mathrm{p}<.05)$ e «inseridos no grupo» $(\mathrm{p}<.025)$ na condição afastados do que na condição próximos. Na condição escuridão verifica-se a tendência contrária. Estes resultados parecem sugerir que os indivíduos se sentem mais à vontade quando se podem orientar em relação a outros indivíduos. No escuro, perante a ausência de contacto visual, é mais confortável sentarem-se perto uns dos outros. Desse modo, é possivel «manter o contacto». Porém, é mais provável que quando estão sentados mais perto uns dos outros na sala iluminada, o «espaço-distância pessoal» (Tall, 1969) de cada um seja violado, sobretudo se não se conhecem uns aos outros. Estas especulações ad hoc deveriam ser objecto de futuras investigações.

Verificou-se uma tripla interacção entre as três variáveis experimentais no item: «Geralmente costumo fazer comentários em voz alta durante a exibição dum filme» (ver coluna 7 
do Quadro 1). Em geral as interacções triplas são extremamente difíceis de descrever, quanto mais de interpretar. Parece que na sala iluminada se observa a mesma interacção entre a proximidade física e a variável de familiaridade que já verificámos antes. Os que se conhecem bem «costumam fazer mais comentários» na condição próximos do que na condição afastados. Entre os que se conhecem mal, acontece o contrário. Esta descoberta parece ser coerente com a teoria das normas, uma vez que as nor- mas têm maior impacto na sala iluminada quando as pessoas se conseguem identificar umas às outras. $\mathrm{Na}$ escuridão, porém, onde o anonimato é maior, a interacção entre a proximidade e a familiaridade é totalmente invertida, embora não possamos deixar de salientar que as diferenças entre os que se conhecem bem e os que se conhecem mal são muito pequenas, talvez porque no escuro os indivir duos têm dificuldade em se identificarem uns aos outros.

\section{QUADRO}

MEDIAS E VALORES F DAS ATTTUDES EM RELAÇÃO A SI PRÓPRIO E AO GRUPO NAS CONDICOOES EXPERIMENTAIS

\begin{tabular}{|c|c|c|c|c|c|c|c|c|}
\hline $\begin{array}{l}\text { (A) } \\
\text { (B) } \\
\text { (C) }\end{array}$ & $\begin{array}{l}\text { (A) Luz } \\
\text { B) Próximo } \\
\text { C) Conhec. }\end{array}$ & $\begin{array}{l}\text { Luz } \\
\text { Próximo } \\
\text { Desco. }\end{array}$ & $\begin{array}{l}\text { Luz } \\
\text { Afastado } \\
\text { Conhec. }\end{array}$ & $\begin{array}{l}\text { Luz } \\
\text { Afastado } \\
\text { Desco. }\end{array}$ & $\begin{array}{l}\text { Escuro } \\
\text { Próximo } \\
\text { Conhec. }\end{array}$ & $\begin{array}{l}\text { Escuiro } \\
\text { Próximo } \\
\text { Desco. }\end{array}$ & $\begin{array}{l}\text { Escuro } \\
\text { Afastado } \\
\text { Conhec. }\end{array}$ & $\begin{array}{l}\text { Escuro } \\
\text { Afastado } \\
\text { Desco. }\end{array}$ \\
\hline \multicolumn{9}{|l|}{ I Normas de comportamento impulsivo } \\
\hline 1. Habituado a fazer comentários & 4.71 & 3.60 & 4.38 & 4.25 & 4.04 & 3.95 & 4.19 & 3.83 \\
\hline $\begin{array}{l}\text { 2. Geralmente incomodado com } \\
\text { comentários }\end{array}$ & 2.86 & 2.95 & 2.27 & 3.12 & 3.00 & 3.25 & 2.87 & 2.89 \\
\hline $\begin{array}{l}\text { 3. Neste momento incomodado com } \\
\text { comentários }\end{array}$ & 2.15 & 1.98 & 1.83 & 1.70 & 1.96 & 2.13 & 1.96 & 1.86 \\
\hline \multicolumn{9}{|l|}{ II Inibição } \\
\hline 4. $\AA$ vontade para fazer comentários & 2.84 & 3.10 & 2.75 & 3.00 & 3.21 & 3.19 & 2.76 & 2.56 \\
\hline 5. Cobaia & 2.09 & 2.76 & 2.12 & 2.42 & 2.29 & 2.57 & 2.92 & 2.28 \\
\hline \multicolumn{9}{|l|}{ III Comportamento impulsivo } \\
\hline 6. Entusiasmado c/ o grupo & 4.21 & 3.39 & 3.81 & 3.50 & 4.21 & 3.22 & 3.56 & 3.49 \\
\hline 7. Incomodado/satisfeito $\mathrm{c} / \mathrm{o}$ grupo & 4.98 & 3.79 & 4.67 & 4.43 & 4.30 & 3.84 & 4.16 & 4.13 \\
\hline 8. Aborrecido-empenhado & 4.52 & 4.01 & 4.16 & 4.32 & 4.33 & 3.71 & 3.90 & 4.23 \\
\hline 9. Apático-animado & 4.94 & 3.76 & 4.24 & 3.90 & 4.40 & 3.59 & 3.79 & 4.07 \\
\hline 10. Frio-caloroso & 4.79 & 4.52 & 4.94 & 4.85 & 4.75 & 4.38 & 4.65 & 4.82 \\
\hline 11. Sensível aos comentários & 3.39 & 3.17 & 3.83 & 3.41 & 3.62 & 3.37 & 3.50 & 3.45 \\
\hline \multicolumn{9}{|l|}{ IV Atracção pelo grupo } \\
\hline 12. Satisfeito c/ o grupo & 5.04 & 4.09 & 4.85 & 4.49 & 4.78 & 4.30 & 4.15 & 4.56 \\
\hline 13. Inserido no grupo & 5.16 & 3.88 & 4.94 & 4.82 & 4.70 & 4.23 & 4.01 & 4.72 \\
\hline \multicolumn{9}{|l|}{ V Satisfação consigo próprio } \\
\hline 14. Livre-reprimido & 4.79 & 4.52 & 4.94 & 4.85 & 4.75 & 4.38 & 4.65 & 4.82 \\
\hline 15. Satisfeito-insatisfeito & 4.38 & 3.49 & 4.53 & 4.22 & 4.42 & 3.62 & 3.70 & 4.34 \\
\hline 16. Descontraído-contraído & 4.56 & 4.22 & 5.07 & 4.71 & 4.94 & 4.66 & 4.61 & 4.75 \\
\hline 17. Aborrecido-empenhado & 4.84 & 4.25 & 4.72 & 4.61 & 4.60 & 3.88 & 4.38 & 4.76 \\
\hline 18. A vontade - constrangido & 4.14 & 3.56 & $3: 84$ & 4.11 & 4.51 & 3.86 & 3.98 & 4.70 \\
\hline \multicolumn{9}{|l|}{ VI Manipulação experimental } \\
\hline 19. Satisfeito por se sentar perto & 3.76 & 3.58 & 3.06 & 3.33 & 3.82 & 3.96 & 3.10 & 3.22 \\
\hline 20. Satisfeito por conhecer toda a gente & 5.27 & 4.47 & 4.91 & 4.66 & 4.84 & 4.43 & 4.86 & 4.74 \\
\hline
\end{tabular}


QUADRO $\Pi$

RESUMO DOS VALORES DE $F$ E $P^{3}$ (d. f. 1,606)

\begin{tabular}{|c|c|c|c|c|c|c|c|c|c|c|c|c|c|}
\hline$\frac{1}{\mathrm{FA}^{\prime}}$ & $p$ & $\underset{\mathrm{FB}}{2}$ & $p$ & $\stackrel{3}{\mathrm{FC}}$ & $p$ & $\stackrel{4}{4}$ & p & $\begin{array}{c}5 \\
F A C\end{array}$ & $\mathrm{p}$ & $\begin{array}{c}6 \\
\text { FBC }\end{array}$ & p & $\stackrel{7}{\mathrm{FABC}}$ & $\mathrm{p}$ \\
\hline & & \multirow{3}{*}{6.14} & \multirow{3}{*}{.05} & 10.73 & .005 & & & & & & & \multirow[t]{2}{*}{5.73} & .025 \\
\hline & & & & 3.95 & .05 & & & & & & & & \\
\hline & & & & 15.43 & .001 & & & 5.71 & .025 & $\begin{array}{l}5.50 \\
6.16\end{array}$ & $\begin{array}{l}.025 \\
.025\end{array}$ & & \\
\hline 6.18 & .025 & & & 12.52 & .001 & & & 3.98 & .05 & $\begin{array}{r}6.30 \\
10.31\end{array}$ & $\begin{array}{l}.025 \\
.005\end{array}$ & & \\
\hline & & & & 13.77 & .001 & & & 3.88 & .05 & 12.72 & .001 & & \\
\hline 4.13 & .05 & & & $\begin{array}{r}16.75 \\
9.58\end{array}$ & $\begin{array}{l}.001 \\
.005\end{array}$ & & & $\begin{array}{l}8.41 \\
7.80\end{array}$ & .005 & $\begin{array}{r}6.79 \\
11.19\end{array}$ & .01 & & \\
\hline & & & & 6.20 & .025 & 5.09 & .025 & 5.50 & .025 & 18.74 & .001 & & \\
\hline & & & & 5.17 & .025 & & & & & 10.27 & .005 & & \\
\hline & & & & & & 4.75 & .05 & & & & & & \\
\hline 5.32 & 025 & & & 4.07 & .05 & & & & & 8.51 & .005 & & \\
\hline & & 17.64 & .001 & 6.55 & .025 & & & & & 13.01 & .001 & & \\
\hline
\end{tabular}

3 Só são referidos os valores de $\mathrm{F}$ e p que estão acima do grau .05 de significância estatística.

\section{DISCUSSÃO}

A teoria das normas parece explicar melhor estes maus resultados do que a teoria da desindividuação. Contrariamente à teoria da desindividuação, mas de acordo com a teoria das normas, os indivíduos que se conhecem bem estão menos inibidos, têm um comportamento mais impulsivo, maior atracção pelo grupo e estão mais satisfeitos consigo próprios do que os indivíduos anónimos e que não se conhecem uns aos outros. Verificou-se algum fundamento para a hipótese de que as normas que emergem entre pessoas que se conhecem bem permitem, ou encorajam mesmo, a expressão de comportamento impulsivo, enquanto que as normas que emergem entre desconhecidos têm uma influência mais restrita. Esta hipótese; extraída da nossa versão da teoria das normas emergentes, parece ser mais indicada do que a teoria da desindividuação para explicar as interacções observadas entre as variáveis familiaridade e grau de iluminação na sala, por um lado, e a distância física, por outro lado.
A conclusão de que a teoria das normas emergentes parece apresentar uma explicação melhor para os nossos resultados deve ser aceite com algumas reservas. Embora esta nossa situação experimental fosse muito mais facilitadora da expressão de comportamento «espontâneo» e «inibido» do que as vulgares experiências de laboratório, incluindo as que foram feitas por Zimbardo (1970), pode-se argumentar que, mesmo na situação por nós criada, o experimentador impunha um certo grau de ordem e estrutura ao nível do comportamento dos sujeitos. Os comportamentos de desindividuação extrema, tal como Zimbardo os descreve, não podiam acontecer. Nesta perspectiva, a nossa experiência não constitui um verdadeiro teste da teoria da desindividuação, embora seja lícito perguntar se alguma vez a poderemos testar com os métodos que temos actualmente à nossa disposição.

Além disso, grande parte da nossa evidência baseia-se nas respostas dos sujeitos ao questionário post-experimental, onde se lhes pedia, individualmente, que descrevessem as reacções 
dos outros e as suas próprias reacções durante o filme. Esta focalização retrospectiva no seu próprio comportamento, pensamento e sentimentos, pode ter conduzido a um grau de individuação ou auto-consciência mais elevada do que tinha lugar durante o período de efectivo comportamento colectivo. Já foi demonstrado que um estado de individuação é provavelmente muito semelhante, conceptual e empiricamente, a um estado de «auto consciência objectiva» (Duval e Wicklund, 1972; Diener e Walborn, 1976; Iches et al.,1978). Um estudo recente sugere que uma pessoa num estado de auto consciência objectiva tenderá mais facilmente a examinar e considerar o seu próprio comportamento segundo os padrões correntes de conduta, do que uma pessoa que tem menos consciência de si própria. (Duval e Wicklund, 1972). Isto pode querer dizer que nos nossos esforços para medir o possível estado interno de desindividuação aumentámos, talvez, a saliência das considerações normativas durante a passagem do questionário post-experimental. Também não possuímos evidência directa da efectiva emergência de novas normas. Pretendemos analisar o conteúdo dos comentários feitos pelos sujeitos para verificar até que ponto eles reflectiam a evolução de novas normas ao longo do tempo. Infelizmente, um defeito na aparelhagem de gravação nem sequer nos permitiu gravar 0 volume de ruído nas várias condições experimentais. A nossa intenção era utilizar o volume de ruído como medida secundária do comportamento impulsivo dos nossos sujeitos.

Já nos referimos ao facto de que «a teoria das normas emergentes, no seu estado actual, nos diz pouco sobre os conteúdos das normas que aparecem nas situações colectivas ...» (Milgram e Toch, 1969:555). A teoria também é bastante vaga quanto aos mecanismos especificos que fazem «emergir» as novas normas. Sugerimos atrás que talvez a teoria da comparação social fornecesse uma explicação sobre a formação das novas normas (Festinger, 1954). A teoria da comparação social parte do princípio que as pessoas estão motivadas para avaliar as suas opiniōes e capacidades. $\mathrm{Na}$ medida em que não possuírem meios objectivos não-sociais ao seu alcance, farão a validação das suas opiniôes em relação à situação, tendo em conta a «realidade social», ou seja, tendo em conta a opinião e comportamento apropriados dos outros (Festinger, 1954; Jones e Gerard, 1967). Este processo de validação envolverá, provavelmente, a comparação social de opinióes, atitudes, crenças e emoções, e pode referir-se não só aos aspectos «informativos» como também aos aspectos «normativos» da situação: como é que uma pessoa se deve comportar a fim de evitar sanções negativas e obter recompensas (Deutsch e Gerard, 1955; Gerard e Rabbie, 1961). Quanto mais ambígua for a situação, mais forte será a tendência para nos compararmos com os outros (Sheriff, 1935; Festinger, 1954; Rabbie, 1963).

Sobretudo nos primeiros estádios ambíguos da formação duma multidão é muito possível que as pessoas estejam motivadas por um processo de comparação social para atingir uma compreensão comum da situação e do tipo de comportamento que delas se espera. Consoante o tipo de atribuições que as pessoas fizerem ao comportamento dos outros (Kelley, 1967), assim tenderão para uma norma mais restrita, ou mais tolerante quanto à expressão de comportamento impulsivo. $\mathrm{Na}$ nossa experiência, por exemplo, se um sujeito só tem a percepção de reacções condenatórias dos seus comentários ou dos dos outros, ou nenhuma percepção de qualquer reacção àqueles, é natural que se desenvolvam normas mais restritivas desse tipo de comportamento do que nas situações em que as pessoas parecem ter reacções muito vivas e emocionais.

Esta forma de «extremização da norma» parece-nos muito semelhante ao processo de polarização frequentemente observado na tomada de decisão por pequenos grupos (Moscovici e Zavalloni, 1969; Rabbie e Visser, 1972; Johnson, Stemler e Hunter, 1977). Nestas experiências existe uma tendência, na discussão em grupo, para acentuar a opinião inicialmente dominante (Meyers, 1978). Embora não haja unanimidade sobre as explicações teóricas da 
polarização nos grupos (Pruitt, 1971), num artigo recente de revisão (Meyers e Lamm, 1976) sugere-se que os processos que mais provavelmente geram a polarização são os das comparações normativas e interpessoais.

$\hat{E}$ natural que as pessoas interpretem uma situação ambígua segundo um quadro de referência a que estão habituadas. $\hat{\mathbf{E}}$ talvez por isto que tem sido observado que as pessoas polarizam o sentido das orientações normativas predominantes na população donde provêm (Moscovici e Zavalloni, 1969). Assim, se já há uma tendência para gritar e barafustar durante um filme entre os nossos sujeitos militares, o processo de comparação social torná-los-á ainda mai tolerantes a este tipo de comportamento. Se já há certas restrições ao comportamento impulsivo, o processo de polarização desviar-se-á no outro sentido.

Todas as condições facilitadoras dos processos de comparação social, como sejam a familiaridade, a proximidade física e a visibilidade, tornarão mais provável a ocorrência de polarização e mudança de normas. Tem sido verificado que os factores ecológicos que facilitam a interaç̧ão social directa produzem mais polarizações e mudança de normas do que a ausência dessas condições (Moscovici e Lécuyer, 1972; Lécuyer, 1975).

Há que salientar que esta interpretação dos resultados não exclui outras explorações adicionais. O nosso objectivo principal era estabelecer uma ligação entre diferentes linhas tradicionais de investigação que nos pareciam não ter uma ligação entre si. Além disso, os processos que têm lugar no seio de multidões e de audiências são tão ricos e complexos que uma só explicação teórica não é suficiente. Há que considerar outros processos psicológicos induzidos pela presença do grupo, tais como os modelos (Bandura, 1973), o contágio comportamental (Wheeler, 1966), a facilitação social (Zajonc, 1965) e a difusão de responsabilidade (Latané e Darley, 1970). Na verdade, poder-se-ia argumentar que estes processos desempenham um papel vital na emergência das normas sociais, as quais, por sua vez, os regulam e controlam. É necessária uma teoria mais explicativa que integre estas várias abordagens. Essa teoria não pode deixar de incluir a hipótese da desindividuação. Porém, perante os nossos resultados e a evidência contraditória contida na literatura (Dipboye, 1977) a teoria da desindividuação contém conceitos centrais, como os de anonimato, presença de grupo, normas, etc., que exigem uma melhor especificação (Diener, 1977).

Zimbardo, 1970:262), por exemplo, afirma que o comportamento impulsivo e contagioso «não é medido pela consciência cognitiva das pressões no sentido da uniformidade de grupo». Todavia, não apresenta qualquer evidência científica que fundamente esta opinião. Antes pelo contrário, os seus próprios estudos de campo sobre a destruição de carros abandonados, que ele considera exemplos cruciais de comportamentos desindividualizado, demonstram a acção de normas sociais. Os carros abandonados por ele foram destruídos em Nova Iorque, enquanto, nas imediações da universidade de Stanford foram cobertos com todo o cuidado. A descrição que ele faz do pai e do filho a saquearem o carro em Nova Iorque, enquanto «a mãe parecia estar de vigia», não nos parece ser nenhum exemplo de pessoas num alto estádio de desindividuação, não conscientes das normas de «qualquer grupo de referência fisicamente ausente» (p.262), incluíndo as normas dos agentes defensores da lei. Além disso, o pai e o filho não eram, obviamente, anónimos um em relação ao outro, mas eram-no, sim, para a patrulha da polícia. De facto, podemos afirmar que a maior parte dos actos de vandalismo, agressão e outras formas de comportamento desindividualizado são cometidos por grupos de conhecidos, cujas normas encorajam e apoiam este tipo de comportamento. Estes indivíduos não são anónimos uns em relação aos outros, mas a pertença ao grupo é que thes permite um certo anonimato e imunização em relação às acções de repressão do mundo externo. 
Zabrac e Miller (1972), que utilizaram um contexto experimental completamente diferente do nosso, chegaram praticamente à mesma conclusão.

Traduçào de Ligia Amâncio

\section{ABSTRACT}

In this paper two conflicting theories were compared with each other: edeidividuation theory which represents a psychological and individualistic approach to the study of collective behavior and kemergent norms theory which reflects a sociological point of view.

In a $2 \times 2 \times 2$ experimental design audiences composed of acquiantances or strangers were watching an emotionally arousing film. Within these two conditions people sat either very close together or further apart in a darkened or lighted room.

Consistently with a modified version of emer. gent norm theory, acquaintances showed more impulsive behavior, contentment with oneself and attraction to the group than strangers who are more anonymous to each other. Moreover, first order interactions of the acquaintanceship condition with the physical proximity and the identifiability variables seemed more in accord with the emergent norm hypothesis than with deidividuation theory. In conclusion it was argued that the concept of anonymity requires further specification.

\section{REFERENCIAS}

ARGYLB, M. (1969)-Social interaction. Aldine, Chicago.

ARONSON, E. (1970) - eSome antecedents of interpersonal attractions, in W. J. Arnold and D. Levine (eds.) Nebraska Symposium on motivation, 1969. 143-173, University of Nebraska Press, Lincoln, Neb.

AUGUSTINUS, M. VAN DER KRUYSSEN, I. A. M. o ZOETE, K. (1972) - Een onderzoek naar aspecten van deindividuatie. Unpublished report I. S. P., Utrecht.

AVENI, A. F. (1977) - «The not-so-lonely Crowd: Friendship Groups in Collective Bebaviors, Socio. metry, 40 (1), 96-99.

BERK, R. A. (1974) - eA gaming approach to crowd behavion, American Sociological Review, 39, 355 . $-373$.

BIDDIS, M. (1977)-The Age of the Masses, Ideas and Society in Europe since 1870, Penguin Books, Hammnondsworth.

BLUMER, H. (1946) - eElementary Collective Groupingss, 178-198, in Alfred McClung Lee (ed.) Principles of Sociology, Barnes \& Noble, New York.
CARTWRIGHT, D. O ZANDER, A. (eds.) (1968) -Group dynamics, Tavistock Publ, London.

COUCH, C. J. (1968)-eCollective behavior: an examination of some stereotypess, Social Problems, $15: 310-322$.

COUCH, C. J. (1970)- Eimensions of association in collective behavior episodes», Sociometry, 33: 457.471 .

DEUTSCH, M. e GERARD, H. B. (1955) - «A study of normative and informational social influence upon individual judgements, Journal of Abnormal and Social Prychology, 51:629-636,

DIENER, E \& WAL.LBOM, M (1976)-eEffects of Self-Awareness on Antinormative Behaviors, Jour. nal of Research in Personality, 10:197-111.

DIENER, E. (1977)- - Deindividuation: Causes and Consequencess, Social Behavior and Personality. 5:143-155.

DIPBOYE, R. L. (1977) - «Alternative approaches to deindividuations, Psychological Bulletin, 84: 1057-1075.

DUVAL, S. e WICKLUND, R. A. (1972) - A theory of Objective Self-A wareness. Academic Press, New York.

EVANS, R. R. (1969)-Readings in collective behavior. Rand MeNally, Chicago.

FESTINGER, L, PEPITONE, A. E NEWCOMB, T, (1952) - «Some consequences of deidividuation in a groups, Journal of Abnormal and Social Psychology, 47:382-389.

FESITNGER, L. (1954) - «A theory of social comparison processess, Human Relations, 7:117-140.

FRENCH, J. R. P., Jr. (1944) - eOrganized and unorganized groups under fear and frustration, in Turner, R. A. \& Killian, L. M. (eds.) Collective Behavior, 2nd ed., 39-43, Prentice Hall, Englewood Cliffs, N. J.

GERARD, H. e RABBIE, QJ, M. (1961) - «Fenr and social comparisons, Journal of Abnormal and Social Psychology, 62:586-592.

HAI.I, E.T. (1959) - The silent language. Doubleday. Garden City, New York.

HARRISON, A. A. (1968)- - Response competition, frequency, exploratory behavior and likings, Journal of Personality and Social Psychology, 9:363-368 .

HOUSE, J. S. (1977) - $\alpha$ The three faces of social psychologys, Sociometry, 40 (2):161-177.

ICHES, W., LAYDEN, M. A. O BARNES, R. D. (1978) - eObjective Self-Awareness and deidividuation: an cmpirical links, Journal of Personality, 46 (1):146-161.

JOHNSON, N. R., STEMLER, J .G. E HUNTER, D. (1977)-eCrowd Behavior as "Risky Shift": a laboratory experiment», Sociometry, 40 (2):183-187.

KELLEY, H. H. (1967). *Attribution theory in social psychologys, in D. Levine (ed.), Nebraska Sym posium on molivation, 192-238. University of Nebraska Press, Lincoln, Neb.

LATANB, B. E DARIBY, J. M. (1970)-The unresponsive Bystander: Why doesn't he help? Appleton-Century-Crofts, New York.

LANG, K. e LANG, G. (1961)-Collective Dynamics, Cromwell, New York.

LE BON, G. (1895)-Psychologie des foules. Translation: The Crowd. Ernest Benn, 1896, London.

LECUYER, R. E. (1975) - ESpace dimensions, the climate of discussion and group decisions?, European Journal of Social Psychology, 4:509-514. 
LOTT, A. J. e LOTT, B. E. (1965)-《Group cohesiveness as interpersonal attraction: $\mathbf{A}$ review of relationships in the antecendent and consequent variables», Psychological Bulletin, 64: 259-309.

MARTIN, E. D. (1970) - $\ll$ The Behavior of Crowds. Harper, New York.

MARX, G. e WOOD, J. (1975) - «Strands of theory and research in collective behavion, in A. Inkeles (ed.) Annual Review of Sociology, 363-428, Annual Reviews Inc., Palo Alto, California.

MEYERS, D. G. (1979) - «Polarizing effects of social interaction», in Brandstätter, H., Davis e Stocker-Kreichgauer, (eds.) G. Group decision making, Wiley, (in press), London.

MEYERS, D. G. e LAMM, H. (1976) - «The group polarization phenomenon», Psychological Bulletin, 83:602-627.

MILGRAM, S., TOCH, M. (1969) - «Collective behavior: crowds and social movements», in $\mathrm{G}$. Lindzey and E. Aronson (eds.) The Handbook of Social Psychology, vol. 4, 2nd ed.

MOSCOVICI, S. e ZAVALLONI, M. (1969) - «The group as polarizer of attitudes», Journal of Personality and Social Psychology, 12:125-135.

MOSCOVICI, S. e LECUYER, R. (1972)- - «Studies in group and group consensus decision I: social space, patterns of communication», European Journal of Social Psychology, 2:261-263.

ORNSTEIN, R. E. (1969) - The psychology of time. Penguin, Hammonsdsworth,

PARK, R. F. (1972)--The crowd and the public. The University of Chicago Press, Chicago.

PRUTTT, D. G. (1971) - «Choice shifts in group decision: an introductory reviews, Journal of Personality and Social Psychology, 20:339-360.

QUARANTELLI, E. L. E WELLER, J. M. (1974)«The structural problem of a sociological speciality: Collective Behavior's lack of Critical Mass», American Journal of Sociology, 9:59-68.

RABBIE, J. M. (1963) - «Differential preference for companionship under threat», Journal of Abnormal and Social Psychology, 67:634-648.

RABBIE, J. M. e VISSER, L. (1972) - «Bargaining strength and group polarization in intergroup negotiationsy, European Journal of Social Psychology, 2:410-416.

RABBIE, J. M. e VISSER, L. (1978)-Internal and external locus of control in passive crowds. Manuscript in preparation. Institute of Social Psychology, Utreche.

RABBIE, J. M., VISSER, L. e VAN OOSTRUM (1979) - «Conflict behavior of individuals, dyads and triads in mixed-motive games», in Brandstätter, H., Davis, J. H. e Stocker-Kreichgauer, G., Group decision making. Wiley (in press), London. ROSS (1908) - Social Psychology. McMillan, New York.

ROTTER, J. B. (1966)- «Generalized expectancies for internal versus external reinforcement», $P s y$ chological Monographs, 80, (nr. 609)

SHERIF, M. (1935) - «A study of some social fac tors in perception», Archives of Psychology, 27 (187): $1-60$.

SIGHELE, S. (1895) - La folla delinquente. Bocca, Turin.

SINGER, J. E., BRUSH, C. A. e LUBLIN, S. C (1965) - «Some aspects of deindividuation: identification and conformityn, Journal of Experimental Social Psychology, I:356-378.

SMELSER, N. (1963) - Theory of collective behavior. Free Press, New York.

SOMMER, R. (1969)-Personal space: the human basis of design. Englewood Cliffs, Prentice-Hall, N. J.

STRYKER, S. (1977) - Developments in «Two Social Psychologies»: Toward an Appreciation of Mutual Relevance. Sociometry, 40 (2):145-160.

TARDE, G. (1903) - The Laws of Imitation. Holt, New York.

TURNER, R. H. (1964) - «Collective behavior», in R, E. L. Faris (ed.), Handbook of Modern Sociology, 382-425, Rand McNally, Chicago.

TURNER, R. H. e KILLIAN, L. (1957)-Collective Behavior. Prentice-Hall, Englewood Cliffs, N. J.

TURNER, R. H. e KILLIAN, L. W. (1972)-Collective behavior. (2nd. ed.), Prentice-Hall, Englewood Cliffs, N. J.

WELLER, J. M. A QUARANTELLI, E. L. (1973)«Neglected Characteristics of Collective Behavior», American Journal of Sociology, 79:665-685.

WHEELER, L. (1966) - «Toward a theory of behavioral contagion», Psychological Review, 73:179. $-192$.

ZABRAC, M. e MILLER, N. (1972)-«Group aggression: the effects of friendship ties and anonymity》, Proceedings of the 80th Annual Convention of the American Psychological Association, 7:211-212.

ZAJONC, R. B. (1965) - «Social facilitation», Science, 149:269-274.

ZIMBARDO, P. G. (1970) - «The human choice: individuation, reason, and order versus deindividuation, impulse, chaos», in W. J. Arnold e D. Levine (eds.), Nebraska Symposium on Motivation. University of Nebraska Press, Lincoln, Neb. 